\title{
Promoting the Construction of Beautiful and Rich China with the Theory of Soil and Water Ecology
}

\author{
Sun Fazheng \\ Shenzhen Nature Ecological Garden Technology Co., Ltd., Shenzhen, China
}

\section{Email address:}

sunfazheng@sina.com

\section{To cite this article:}

Sun Fazheng. Promoting the Construction of Beautiful and Rich China with the Theory of Soil and Water Ecology. Science Discovery. Vol. 8, No. 2, 2020, pp. 27-31. doi: 10.11648/j.sd.20200802.11

Received: March 18, 2020; Accepted: May 26, 2020; Published: June 4, 2020

\begin{abstract}
Started from the problems and perplexities of ecological environment in China, the scientific principle and value of the theory of soil and water ecology are discussed. It is thought that the theory of soil and water ecology clarifies the complicated problems of ecological environment. Environmental pollution can be controlled, but it is only a matter of time and cost. Soil and water ecology is the root of ecological environment problems. The clean water and green mountain are destroyed, which cannot be restored. With the theory of soil and water ecology, the idea that clean water and green mountain are golden and silver mountains is read, as well as the way of turning clean water and green mountain into golden and silver mountains and its different impacts on eco-environment. The developed and underdeveloped areas should treat the idea that clean water and green mountain are golden and silver mountains. The application of the theory of soil and water ecology in soil and water conservation broadens the space of soil and water conservation, and it is necessary to establish a national commission for the conservation of soil and water ecology. The theory of soil and water ecology is the golden key to solve the problems of contemporary ecological environment and the theoretical basis for building a beautiful and rich China.
\end{abstract}

Keywords: Ecological Environment, Soil and Water Ecology, Clean Water and Green Mountain,

Golden and Silver Mountains, Beautiful and Rich

\section{用水土生态理论推进美丽富饶中国实践}

\section{孙发政}

深圳市大自然生态园林技术有限公司, 深圳, 中国

\section{邮箱}

sunfazheng@sina.com

摘要: 本文从我国生态环境的问题与困惑出发, 论述了水土生态理论的科学原理和科学价值, 认为水土生态理论厘清 了错综复杂的生态环境问题，环境污染是能够治理的，只是时间和成本问题; 而水土生态是生态环境问题的根源，绿 水青山破坏了，无法还原。用水土生态理论阐述了绿水青山就是金山银山的理念，以及绿水青山转化为金山银山的方 式和对生态环境的不同影响。由于发展阶段不同, 绿水青山就是金山银山的理念需要科学地来认识和理解。水土生态 理论在水土保持上的应用, 拓宽了水土保持空间, 有必要成立国家水土生态保持委员会。水土生态理论是解决当代生 态环境问题的金钥匙，是建设美丽富饶中国的理论基础。

关键词: 生态环境, 水土生态, 绿水青山, 金山银山, 美丽富饶 


\section{1. 前言}

2004年11月，笔者作为《中国发明与专利》杂志封 面人物接受记者专访时首次提出水土生态概念, 至今 16 年以来, 结合丰富的生产实践和世界各地的科学考察, 发表了一系列关于水土生态理论的论文, 基本形成了较 为完整的水土生态理论体系。水土生态理论是水土保持 科学认识观的深化和发展, 是生态科学的创新与拓展; 水土保持学与生态学的交叉和融合, 还将会产生一门新 的学科一一水土生态学。更为重要的是, 水土生态理论 是解决当代生态环境问题的重要向导, 是保护地球生态 环境的重要理论支撑。

\section{2. 我国生态环境的问题与困惑}

\section{1. 生态环境理论上值得探讨}

生态环境的提法在理论上是有争论的 [1], 只不过 是如今普遍采用了, 也算约定俗成。但不是说生态环 境的提法是科学的。“环境”是相对于中心事物而言, 是指主体周围的空间及空间中存在的事物, 从建设美 丽中国的实践上看, 它包括自然环境及人文环境中的 物质成果部分。而生态学, 最早是由德国动物学家 Haeckel于1869年提出的, 是研究有机体与环境相互关 系的科学; 1909年, E. Warming提出植物生态学概念; 1935年, 英国植物学家A.G.Tansley提出生态系统理论; 2004年, 中国生态科学家孙发政提出水土生态理论 [2-7]。生态的内涵, 是指生物之间及其与非生物之间 的关系。可见 “生态”与“环境”两者在内涵上是有本质区 别的。生态就是生态, 环境就是环境。因此, 生态环 境的提法并不严谨, 而生态与环境的提法才是准确的。 在建设美丽中国的进程中, 仅讲自然景观和人文景观 的美丽还是不够的, 江山富饶美丽才是建设美丽中国 的本质要求。这一点, 需要从理论上阐明清楚, 避免 只讲生态环境美丽, 而不讲经济发展; 或只讲经济发 展, 而不讲生态环境保护。

\section{2. 制定政策的理论依据有待加强}

由于生态环境在理论上有不足, 往往给实际工作带 来迷茫, 比如, 将“生态”与 “环境”混为一谈, 认为是一 个概念, 实践上抓不住问题的要害。目前我国生态环境 部门还是搞的环保老一套, 主要抓环境污染防治。而生 态环境最大的问题是什么? 应该是水土生态问题[5]。水 土保持虽然是基本国策, 但还是只有水利部门主管。生 态环境领域, 包括水土保持, 常常以问题为导向, 在出 现了问题之后, 再去亡羊补牢, 代价是高昂的, 有的再 也无法挽回。这些年来, 关于生态环境问题的不同声音 依然存在, 生态与经济孰是孰非, 莫衷一是; 政策制定 上也有反复现象。原因在于生态环境缺乏完善的理论遵 循, 理论落后于实践。

\section{3. 水土保持理论有待升华}

1934年治理黄河泥沙时提出的水土保持概念, 一直沿 用至今[6]。而经济社会已经发生了翻天覆地的变化, 传统 水土保持理论已经难以适应新的发展, 通常用水土保持生 态建设、水土保持生态治理等来表述当代水土保持实践。 一些地方已经将水土保持部门改为生态环境中心, 海绵城 市建设也独立于水土保持之外。可见，水土保持理论的创 新非常之迫切, 否则, 水土保持空间将越来越小, 学科的 发展将严重僵化。

\section{4. 水土生态理论还没有引起足够的重视}

虽然生态环境错综复杂, 但是用水土生态理论来分析, 也就一目了然。地球上的生态环境问题无非归处为 3 大原 因: 环境污染、水土生态退化、资源衰竭。三者之间有区 别, 有联系, 而水土生态是最大的生态环境问题。防止水 土生态退化, 就抓住了生态环境问题的“牛鼻子”。在规划、 建设、管理方面, 需要做好显性和隐性水土流失防治, 减 少对自然水土生态的侵占和破坏, 统筹山水林田湖草系统 治理; 其次, 防治环境污染, 保护和合理利用自然资源。 大气雾䨪, 从源头上讲是次生的, 是由于自然的水土生态 被破坏、大地钢筋水泥化后, 人为活动造成的次生的空气 污染, 绿水青山不会产生雾皬。水土污染问题, 需要做好 源头防控, 发挥自然的净化功能, 养殖类粪便还可资源化 利用, 变废为宝。

\section{3. 水土生态理论是解决当代生态环境问题的金 钥匙}

没有先进的理论，很难有成功的实践。有时候出发点 是好的, 而结果往往适得其反, 事如愿违。在理论上对生 态环境进行剖析, 由表及里, 抓住事物的本质, 事半功倍。 相反, 理论上含糊不清, 就找不出实际问题的深层次原因, 往往“头痛医头, 脚痛医脚”、“抓了芝麻, 丢了西瓜”。水 土生态理论是在丰富的实践基础上, 建立起来的先进的理 论体系, 是认识和解决当代生态环境问题的一把金钥匙。

\section{1. 水土生态理论厘清了错综复杂的生态环境问题}

地球上生态环境问题可以归处为 3 大原因: 环境污染、 水土生态退化、资源衰竭。三者之间有区别, 又有联系, 而水土生态退化是最大的生态环境问题。生态环境问题的 根本原因, 是人类没有处理好人与水的关系、人与土壤的 关系、人与植被的关系, 也就是人与水土生态的关系。

环境污染: 从污染物看, 有固态、气态、液态。据联 合国环境署估计, 每年有超过 640 万吨垃圾进入海洋, 海 洋正沦为垃圾场。英国斯凯特岛一头鲸鱼在岸边搁浅而亡, 研究人员解剖它的尸体, 竟然在它的胃里发现了足足 4 公 斤的塑料垃圾。从被污染的对象看, 有水、土、大气的污 染。雾䨪容易看得见, 而地下水、河湖及土壤污染, 需要 检测手段加以判别。此外, 还有光、噪音、重金属、放射 
物等污染。环境污染问题, 特别是污染存量, 总归能够得 到解决, 不过是时间和成本问题。

水土生态退化: 人类与自然的关系, 寻根溯源归结 为人与水的关系、人与土壤的关系、人与植被的关系。地 球上水土与植被相互关联、相互促进与发展的生态平衡关 系是水土生态的深刻内涵, 广义上说, 水土生态是指水、 土、植被在其运动和演化过程中的一切关系的总和。地球 上的水、土、植被都是运动和变化的, 凡是有水土的地方, 必然有植物的生长; 植物的生长反过来保育水土资源。森 林具有涵养水源、保持水土、固碳放氧、改善气候等生态 功能; 水是光合作用制造有机物的原料, 植物体一般含有 60 90\%的水分; 土壤中的矿物质、氧、二氧化碳必须溶 于水后, 才能被吸收和在植物体内运转。水、土、植被是 相辅相成的有机整体。森林被砍伐、草原被破坏、农田被 侵占、青山被开挖、河湖被填平, 这些水土生态被破坏, 是当代水土生态退化的主要表现。环境污染了还可以净化、 治理和还原, 而自然的水土生态被破坏, 绿水青山被开挖 以至于钢筋水泥化, 则无法还原。人要与自然和谐, 做到 了人与水、人与土、人与植被的和谐, 才能实现人与自然 的和谐。

资源衰竭：地球上的水土生态是由水（江、河、湖、 冰川、雨水）、土（土壤、岩石、矿藏）、植被（森林、 草原、园林、农作物) 三大要素在时空上构建的自然景观 与自然环境。无论是生态、资源还是环境, 都离不开水、 土、植被三大要素, 三者是生态的主体, 又是环境、资源 的载体。自然的水土生态被破坏, 会造成资源衰退、动植 物减少、物产萎缩。地球上的矿藏资源, 因人类开采已经 越来越少, 有的已趋于枯竭。资源衰竭和环境污染, 加速 水土生态退化; 水土生态退化, 加重资源衰竭和环境污染。 水土生态退化是最大的生态环境问题, 是生态问题的本质。

3.2. 水土生态理论是关于自然界普遍规律的新认识, 既 是认识论, 又是方法论。在农业、林业、水利、规 划、国土、资源、环境、园林、水土保持等领域, 具有重要的科学价值。

从源头上看, 人类的一切生产活动, 都是在与水、土、 植被打交道。农业上，有“土、肥、水、种、密、保、管、 工”八字宪法; 工业上, 有原油、煤炭、矿藏开采, 厂矿 用地; 商业上, 有建高楼、园区; 水利上, 有筑坝蓄水、 发电; 交通上, 有修筑公路、机场, 等等。无不涉及水、 土、植被, 从而改变着地球上的水土生态。水土生态的改 变是一切生态环境问题的根源[4]。

地球上水、土、植被是相互联系、相互促进的有机整 体, 又有各自运动的自然规律。土壤和植被具有地带性分 布规律。南方有红壤, 北方有黑土; 不同纬度、海拔, 分 布着不同的植物群落。降雨有时空分布, 河湖有汛期和旱 期, 海水有涨潮和落潮。这些就是水土生态规律, 人类活 动需要遵循和利用水土生态规律。作为陆地生态系统, 要 素十分复杂, 但从水土生态理论来认识复杂的生态系统, 抓住水、土、植被主要矛盾, 其它问题容易迎刃而解。

水土保持着眼点在于水土资源的保护和利用。水土不 分家, 有了水土保持; 水土植被不分家, 有了水土生态理
论。保持水土的目的, 是为了发展植被 (包括农作物、果 树、牧草); 植被繁茂与稳定, 是保持水土的初衷, 离开 植被谈水土, 显然无意义。水土生态理论在水土保持上的 应用, 使水土保持升级为水土生态保持, 拓展了水土保持 空间, 真正成为生态文明建设的主体 [5]。水土保持与生态 学的交叉和融合, 还将会产生一门新的学科一一水土生态 学。

\section{3. 水土生态理论既微观又宏观, 不仅关系到一草一木, 还关系到气候变化。}

人类活动无休止地改变着陆地和海洋的水土生态平 衡, 将森林、草原、湿地变为耕地, 将山川、河流、农田 变为城市、机场、公路、工业园区, 人类所依赖的自然的 水土生态正在以比人类历史上任何时候都快的速度退化。 自1980年以来, 地球温室气体排放量翻了一番, 全球平均 温度上升了至少 $0.7^{\circ} \mathrm{C}$, 气候变化对遗传多样性、物种多 样性和生态系统多样性产生了深刻的影响。

随着工业革命的开始, 地球上约有 $75 \%$ 自然的水土生 态被改变, 原有水土生态平衡被打破, 大量温室气体排放 到大气中。研究揭示, 如今大气中的 $\mathrm{CO}_{2}$ 含量可能比过去 300 万年中的任何时候都要高。2018下半年以来, 格陵兰 岛的冰盖融化速度是过去至少 350 年以来最快的, 比工业 革命前高 $50 \%$ 以上, 比 20 世纪快 $33 \%$ 。保护水土生态, 是 从源头上阻止全球变暖, 避免气候变化给人类造成不可逆 转的灾难性后果 $[4]$ 。

\section{4. 用水土生态理论推进美丽富饶中国实践}

生态文明建设已成为我国全社会的普遍共识, 写入了 党章和宪法。绿水青山就是金山银山的理念深入人心, 统 筹山水林田湖草系统治理稳步推进, 美丽富饶中国逐步呈 现。昔日杀鸡取卵的经济发展方式得到了根本改变, 山不 像山、水不像水、天不像天的年代已经基本结束。虽然付 出了昂贵的代价, 但理论的探索有了丰硕成果, 水土生态 理论为建设美丽富饶中国奠定了理论基础[7]。

\section{1. 绿水青山是水土生态的外在表征}

绿水青山是由水、土、植被三大要素构起的自然地貌 景观, 有众多子系统组成的一个大的生态系统, 这个生态 系统在一定时间和空间内, 生物成分和非生物成分之间, 通过物质循环和能量流动, 相互作用、相互依存, 是一个 统一整体。绿水青山是泛指地球上多样性的自然生态系统, 如森林生态系统、草原生态系统、农田生态系统, 山地生 态系统, 湿地生态系统, 等等。无论哪种类型的生态系统, 都是由生物成分和非生物成分组成。生物成分中有绿色植 物、动物、细菌、真菌等。非生物成分中有阳光、水、空 气、土、有机质、矿物质等; 每一种成分都很重要, 不可 或缺, 但还是有区别的。在生物成分中, 绿色植物是初级 生产者, 太阳辐射的能量唯一靠具有叶绿素的植物进行光 合作用而进入生态系统, 是关健要素; 非生物成分中水土 是物质循环的基础, 起主导作用。人类活动直接干预和改 变的是水、土、植被三大要素。绿水青山中的水、土、植 
被三大要素, 相互联系、相互促进与演化的关系, 构建了 复杂的生态系统骨架。水土生态是一切生态系统的核心, 抓住了水土生态这个要领, 也就抓住了生态环境问题的本 质。人类的生产活动, 从源头上讲, 都是在与水、土、植 被打交道, 在获得物质财富的同时, 改变着生态环境。地 球上绿水青山是经过亿万年演化而来的, 比人类的历史还 要久远, 正因为有绿水青山, 才有了人类的诞生、演化和 发展。绿水青山还是各种动物的天然家园, 物种多样性的 自然宝库[8]。

\section{2. 金山银山是水土生态的内在要求}

绿水青山具有生态、环境、资源的多重属性, 蕴含着 丰富的自然资源和物质财富，可以形象地称之为金山银山。 这里的金山银山有双重含义，一是尚未被开发利用的自然 资源, 具有科研、旅游、生态、环境的价值; 二是已将自 然资源转化为物质财富、现实的经济效益。由此, 金山银 山是可持续发展的永恒主题。绿水青山就是金山银山的理 念, 是可持续发展的必然要求, 也是水土生态的内在要求。 水土生态理论在水土保持上的应用, 就是保护环境、改善 生态, 发展经济。因地制宜地发展农业、林业、草业等相 关产业, 是绿水青山转化为金山银山的方式之一。冊庸置 疑, 人类要生存, 经济要发展, 工业化与城市化是人类的 进步, 必然的趋势, 财富增长的重要途径, 也是绿水青山 转化为金山银山的方式之一 [9-10]。绿水青山转化为金山 银山, 需要遵循水土生态规律, 实现工业化与城市化的可 持续发展, 生态与环境的可持续维护。

\section{3. 用水土生态理论推进美丽富饶的中国实践}

用水土生态理论推进美丽富饶的中国实践 [11-14], 必 需遵循绿水青山就是金山银山的理念，同时，处理好以下 几个问题:

a) 水土生态是生态环境的主要矛盾, 要着力解决好 显性和隐性水土流失, 有了肥沃的水土, 才有繁茂的植被, 进而发展生产和改善生态环境。水土生态涉及到水土保持、 国土、林草、环境等部门, 发挥好水土保持部门现有机构 的力量, 还应成立国家水土生态保持委员会, 统筹多部门 力量, 强力推进美丽富饶中国的实现。

b) 发展仍然是当代之要。创造物质财富的生产活动, 就是不断地改变着水、土、植被, 从而也改变着生态环境。 土地城市化之后的水土生态, 可以通过园林绿化、生态修 复等提升人居环境, 对于养殖业的污染, 无需诚惶诚恐, 可以资源化利用, 水体、土壤、植被也有一定的净化污染 的能力。

c）经济发展了的绿水青山、蓝天白云, 才是美丽富 饶中国的推进方向。不能为了绿水青山、蓝天白云, 而经 济上无所作为。经济发达地区, 需要守护好绿水青山、蓝 天白云, 增进福祉。不同的发展阶段, 特别是经济发达地 区和经济欠发达地区应有区别地对待生态环境保护; 绿水 青山就是金山银山的理念需要科学地来认识和理解。

d）从源头上保护好水土生态, 需要以水、土、植被 为抓手, 生产建设尽量做到不破坏原生地貌, 实现人与自 然和谐。一个地区的生态环境如何, 只要看这个地区水土
生态如何, 水、土、植被是生态环境的基础, 有了好的基 础, 空气质量是可控的。

e）如今新兴产业热点领域已经出现产能过剩态势, 如光伏风电产业工业园等, 这些产业的建设, 曾经破坏和 占用的绿水青山, 由于地形地貌的改变及钢筋混凝土的建 设, 再也无法恢复到原有的水土生态。因此, 从源头上保 护好水土生态, 显得尤为重要。

\section{5. 结语}

科学探索不断地向宏观拓展、向微观深入, 交叉、融 合、汇聚在加速, 一些基本科学问题孕育着重大突破, 可 望催生新的重大科学思想和科学理论。水土生态理论是从 “ 0 到 1 ”的基础研究, 原始创新, 是关系到生态环境根本性 和全局性的重大科学理论问题, 对于地球生态环境保护具 有重要的战略意义; 水土生态理论是解决当代生态环境问 题的认识论和方法论, 是建设美丽富饶家园的理论基础。

\section{参考文献}

[1] 孙发政.关于水土生态与水土生态保持的再认识[J].中国水 土保持,2010（1）：7-9.

[2] 孙发政.论水土、水土生态与水土生态保持[J].中国水土保 持,2006(11):14-16。

[3] 孙发政.关于水土生态与水土生态保持几个问题的探讨 [J]. 水土保持学报, 2011,25 (2) :262。

[4] Sun Fazheng.P ilosophical Thinking on Soil and Water Ecology $[\mathrm{J}]$. eteorological and Environmental Research, 017(8):29-33.

[5] 孙发政.创新水土保持理论 攀登生态保护和生态建设制高 点[J].中国水土保持, 2007（6）：13-14。

[6] 孙发政.试论将“水土保持”改称“水土生态保持”的科学性 [J]. 中国水土保持, 2005（8）:22-23。

[7] Sun Fazheng. Theory and Practice of Soil and Water Ecology [J]. ournal of Landscape Research, 2018, 10(2):71-74.

[8] Sun Yuan,Sun Fazheng.Carry forward Soil and Water Ecological Culture and Build Rich and Beautiful Home [J]. Meteorological and Environmental Research, 2014(10):11-14.

[9] Sun Fazheng.Water and Soil Conservation in Taiwan Based on Theoretical Research of Water and Soil Ecology [J]. Journal of Landscape Research, 2016, 8(5):90-92, 96.

[10] 孙发政.基于水土生态理论研究视野下的城市水土保持 $[\mathrm{J}]$. 风景园林,2013（5）：35-38。

[11] 孙发政.从日韩考察看水土生态保持的普遍意义[J].中国水 土保持,2008(8):23-24。

[12] 孙发政.美国和加拿大水土生态环境考察启示 $[\mathrm{J}]$.草原与草 坪, 2011,31(1):94-96。 
[13] 孙发政.非洲考察及其水土生态启示 [J]. 中国水土保 持,2010(6):5-6。
[14] Sun Fazheng.Development of Prataculture and Construction of Landscape City Based on the Rule of Water and Soil Ecology [J]. Journal of Landscape Research, 2015, 7(5):38-40. 